\title{
The nexus between the oil price and its volatility risk in a stochastic volatility in the mean model with time-varying parameters
}

\author{
Mehmet Balcilar ${ }^{\mathrm{a}, \mathrm{b}, \mathrm{c}, \mathrm{d}, *}$ \\ ${ }^{a}$ Eastern Mediterranean University, Northern Cyprus, via Mersin 10, Turkey \\ ${ }^{\mathrm{b}}$ Montpellier Business School, Montpellier, France \\ ${ }^{\mathrm{c}}$ University of Pretoria, Pretoria, South Africa \\ ${ }^{\mathrm{d}}$ Economic Research Form, Cairo, Egypt \\ e-mail: mehmet@mbalcilar.net \\ and \\ Zeynel Abidin Ozdemir ${ }^{\mathrm{e}, \mathrm{f}}$ \\ ${ }^{\mathrm{e}}$ Gazi University, Ankara, Turkey \\ ${ }^{\mathrm{f}}$ Economic Research Form, Cairo, Egypt \\ e-mail: zabidin@gazi.edu.tr
}

\begin{abstract}
High price volatility in oil markets creates uncertainty and risk, and increased risk premium may feed back into the prices. This study investigates the dynamic nexus between oil price and its volatility for oil spot and futures markets by means of stochastic volatility in the mean model with time-varying parameters in the conditional mean. The study finds substantial timevariation about the impact of oil price volatility on oil price return in both spot and 1-month to 10 -month futures markets. The oil price return volatility has a positive impact on oil price return series over the sample period form the mid-1980s to 2017s except for four very short time periods, which correspond to collapse of OPEC in 1986, invasion of Kuwait in 1990/91, Asian crisis in 1997/2000 and the Global Financial Crisis in 2008. While the oil price return volatility has a positive impact on oil prices, it has limited negative impact on oil prices during periods corresponding to these historical events. Moreover, the findings from this study point out to the existence of a negative and small effect of the lagged oil return series on its volatility for both the spot and futures markets.
\end{abstract}

Keywords: Oil price; Oil price uncertainty; Spot and futures markets; Stochastic volatility; State-space.

JEL Codes: C22, E32

${ }^{*}$ Corresponding author 


\section{Introduction}

The uncertainty of oil prices is likely to decrease current investment according to the theories of investment under uncertainty and real options. Such theories about firm-level investment decisions are advanced by Henry (1974), Bernanke (1983), Brennan and Schwartz (1985), Majd and Pindyck (1987), Brennan (1990), Gibson and Schwartz (1990), Triantis and Hodder (1990), and Aguerrevere (2009). Bernanke (1983) and Elder and Serletis (2010) contends that firmlevel investment decisions can produce macro-level cyclical fluctuations. The theoretical models advanced by Bernanke (1983) are concerned with the volatility of the real price of oil at time periods relevant to investment decisions (e.g., Edelstein and Kilian, 2009, Kilian and Vigfusson 2011, Alquist et al. 2013) rather than one-month- or one-quarter-ahead volatility of the real price of oil. In this case, the demand for inventories determines the price of oil. The expectations of forward-looking traders influence the changes in real prices and the inventories.

On the other hand, others consider the shocks to the flow supply of oil and the flow demand for oil as important determinants of oil price. This argument motivates us to add to the literature by providing a new empirical perspective between oil price and its uncertainty using the time varying parameter stochastic volatility in mean (TVP-SVM) model.

High oil price volatility creates increased uncertainty and risk in the economy. Increases in uncertainty and risk have substantial effects on the economy. The direct effects of uncertainty about oil prices on the real economy have not been studied extensively. Pindyck (1991) suggests that oil price uncertainty may have played a role in the recessions of 1980 and 1982. Similarly, Ferderer (1996) reports adverse effect of oil price uncertainty on output in the United States over the 1970-90 period. Similar evidence is reported by Hooker (1996) over the 1973-94 period. On the contrary, Edelstein and Kilian $(2007,2009)$ find little indication of asymmetries 
that would generate an uncertainty effect. They follow the approach of Elder and Serletis (2009, 2010, 2011) and Bredin et al. (2011), and utilize a vector autoregressive (VAR) model in order to gauge the impact of oil price uncertainty. Oil price uncertainty is considered as a generalised autoregressive conditional heteroskedasticity $(\mathrm{GARCH})$ process. This has been a popular approach to model macroeconomic uncertainty while investigating its effect on macroeconomic performance (Chua et al., 2011). Using this approach Elder and Serletis (2010) find that oil price uncertainty had an adverse and statistically significant effect on durables consumption, aggregate output and several measures of investment in the US. They also find that accounting for the effects of oil price volatility tends to worsen the adverse dynamic reaction of the real economy to a negative oil price shock, while diminishing the reaction to a positive oil price shock.

Crude oil price went through intense changes in its behaviour in the last five decades. This feature of the crude oil price is often ignored; such extreme shocks include the OPEC oil embargo of 1973-1974, the Iranian revolution of 1978-1979, the Iran-Iraq War of 1980-1988, the first Persian Gulf War of 1990-91, the oil price spike of 2007-2008, and the oil price plunge of 2015. In recent years, the researchers increasingly emphasized the importance of shifts in the demand for oil and provided evidence that oil demand shocks have been important in major crude oil price shock incidences especially since the 1970 (Kilian, 2010, 2014, 2016). These shocks can cause sudden shifts in the mean of oil prices. Further, they can affect the unconditional and conditional variances of oil price (Charles and Darné, 2014). The conditional variances are used as a proxy for oil price uncertainty and may also involve breaks in the GARCH process parameters. Salisu and Fasanya (2013) tested for structural breaks in the volatility of West Texas Intermediate (WTI) and Brent oil prices and found evidence in favour two structural breaks in 1990 and 2008, which correspond to invasion of Kuwait in 1990/91 
and the Global Financial Crisis in 2008. More recently, the univariate or multivariate GARCH models have been used to analyse macroeconomic data, as in Chua et al. (2011) and Elder and Serletis (2010). The latter authors studied the effect of oil price shocks volatility on macroeconomic variables and vice-versa. Moreover, a number of researchers such as Blake and Roberts (2006), Radetzki (2006), Reboredo (2013), Behmiri and Manera (2015), Raza et al. (2016), Bhatia et al. (2018) and Dutta (2018) investigate impacts of oil volatility shocks on commodity markets. However, all these studies are limited to models with constant coefficients.

A wide variety of macroeconomic time series exhibit structural instability as shown in the literature (see, e.g., Canova 1993; Cogley and Sargent 2001; Koop and Potter 2007, among many others). One popular method to model this structural instability is the time-varying parameter (TVP) model. In such models the parameters in the conditional mean can develop slowly over time. The importance of permitting time-varying volatility in macroeconomic time series is also emphasized in the literature. In such models, the heteroscedastic errors are usually modelled employing a stochastic volatility specification (see, e.g., Cogley and Sargent 2005; Primiceri 2005). For macroeconomic forecasting, D'Agostino, Gambetti, and Giannone (2013) found that both structures are decisive in generating precise forecasts. Chan (2017) developed a model where the stochastic volatility has a direct and time-varying impact on the variable considered. He builds upon the stochastic volatility in mean (SVM) model of Koopman and Uspensky (2002). The latter model was originally advanced for financial time series as an alternative of the ARCH-M model of Engle, Lilien, and Robins (1987). Our study is the first in the literature that considers time-varying impact of uncertainty on the oil prices. We build on the Bayesian TVP-SVM model approach of Chan (2017) and allow time-varying uncertainty effect on the oil prices. This approach optimally allows time-varying impact and therefore robustly accounts for structural breaks. 
The main focus of this study is to determine the dynamic linkages between oil price and oil price uncertainty for the crude oil spot and future series. To serve this purpose, we use the SVM component in the conditional mean model. The modified SVM model allows us to study the effect of the volatility feedback, namely, how oil price volatility affects the level of oil price and vice-versa. There is a large literature that examines the relationship between oil price and oil price uncertainty. In contrast to the previous studies that consider only models with constant coefficients in the conditional mean, the time-varying parameter model allows us to assess if the oil price-oil price uncertainty relationship has changed over time. This paper investigates the dynamic nexus between oil price and oil price uncertainty series for the crude oil spot and futures markets for 1-month to 10-month maturities series. The data used are the log returns of monthly crude oil spot and futures contracts for 1-month to 10-month maturities traded on the New York Mercantile Exchange. Our paper contributes to the literature in four ways. First, it is the first paper, to the best of our knowledge that explicitly allows time varying uncertainty to affect the oil price in the TVP-SVM model. The TVP-SVM approach optimally models the time-varying affects and therefore robustly incorporates the structural breaks. Second, our approach based on the SVM model treats the uncertainty chocks in a stochastic manner while the GARCH models used by the previous literature treat the volatility deterministically. Third, our approach additionally allows the oil price to influence its volatility. Low and high oil prices have different market conditions and therefore oil price is very likely to affect its volatility. Fourth, we examine both the spot and 1-month to 10-month oil futures markets to show whether our findings generalizes to futures markets.

Our results show that there is substantial time-variation in the coefficient measuring the effect of uncertainty on the oil price. We find that the uncertainty has a positive effect on the oil price for most of sample period except for four short breaks corresponding to known 
historical events such as the collapse of the OPEC in 1986, invasion of Kuwait in 1990/91, Asian crisis in 1997/2000, and the Global Financial Crises in 2008. ${ }^{1,2}$ Although uncertainty significantly increases the oil price in most of the sample period from mid-1980s to $2017 \mathrm{~s}$, it has limited negative impact on oil price series in four break periods corresponding to collapse of OPEC in 1986, invasion of Kuwait in 1990/91, Asian crisis in 1997/2000 and the Global Financial Crisis in 2008. The results from this study also indicate that the coefficient associated with the lagged oil return series for the crude oil spot and futures markets for 1-month to 10month maturities is estimated to be quite small and negative. This means that the oil price has negative and limited impact on its volatility.

The paper is organised as follows: the next section outlines the methodology. Section 3 presents and explains the features of the data. Section 4 presents the analysis of the empirical results from the TVP-SVM. The last section presents the conclusion.

\section{Methodology}

Recent literature has demonstrated that many macroeconomic time series show structural instability (see Stock and Watson 1996; Cogley and Sargent 2001, among many others). An optimal approach for modelling structural instability is the TVP approach in which some parameters of a model evolve over time in stochastic manner. In this paper, we allow the impact of oil price uncertainty on the oil price to be time-varying, capturing any structural instability in the macroeconomic environment that may alter the price-price uncertainty relationship.

\footnotetext{
${ }^{1}$ Salisu and Fasanya (2013) found two structural breaks in oil price volatility, which correspond to invasion of Kuwait in 1990/91 and the Global Financial Crisis in 2008. These two breaks are also confirmed in our study.

${ }^{2}$ The detection of these four shifts in the effect of uncertainty shows the richness and power of the TVP-SVM model. The TVP-SVM model successfully captures the changes in the dynamics of the markets corresponding to historically known events.
} 
Although, there are several approaches to measure oil price uncertainty, a popular approach is the stochastic volatility (SV) model of Koopman and Hol Uspensky (2002), which usually fits better to time series that show conditional heteroskedasticity. Compared to the GARCH models, where the volatility specified with a deterministic function, volatility in the SV models is specified as a latent stochastic process that allows volatility shocks. In this paper, following Chan (2017), we combine the TVP and SV approaches in analysing the oil price and oil price uncertainty (volatility) relationship, as a flexible model that robustly allows structural breaks and stochastic volatility shocks. Additionally, we allow the past oil price to affect the oil price uncertainty. The TVP-SVM model is specified as follows:

$$
\begin{aligned}
& y_{t}=\tau+\alpha_{t} e^{h_{t}}+\varepsilon_{t}^{y}, \quad \varepsilon_{t}^{y} \sim \mathcal{N}\left(0, e^{h_{t}}\right) \\
& h_{t}=\mu+\phi\left(h_{t-1}-\mu\right)+\beta y_{t-1}+\varepsilon_{t}^{h}, \quad \varepsilon_{t}^{h} \sim \mathcal{N}\left(0, \sigma^{2}\right) \\
& \alpha_{t}=\alpha_{t-1}+\varepsilon_{t}^{\alpha}, \quad \varepsilon_{t}^{\alpha} \sim \mathcal{N}\left(0, \omega^{2}\right)
\end{aligned}
$$

where $y_{t}$ is the $\log$ first differences of oil price, $\varepsilon_{t}^{y}, \varepsilon_{t}^{h}$ and $\varepsilon_{t}^{\alpha}$ are mutually and serially uncorrelated disturbances. The log volatility $h_{t}$ follows a stationary ARX(1) process with $\phi<$ 1. In the model given in Equations (1)-(3), $\exp \left(h_{t}\right)$ is the variance of the transitory component $\left(\varepsilon_{t}^{y}\right)$ of $y_{t}$, therefore, we can interpret $\alpha_{t}$ as the impact of the transitory oil price volatility on the level of oil price. The parameter $\beta$ measures the impact of oil price on its volatility. In the empirical section, the model in Equations (1)-(3) is estimated using the efficient Markov chain Monte Carlo (MCMC) sampler developed in Chan (2017). ${ }^{3}$ Our specification differs from Chan (2017) by constant mean specification $\tau$ in Equation (1).

\footnotetext{
${ }^{3}$ See Chan (2017, p. 27) for the priors used in the estimation.
} 
The process $\left\{h_{t}\right\}_{t=T}^{0}$ defined in Equation (2) defines the log conditional variance and unobserved and, thus, it is a latent process with initial state $h_{0}$ distributed according to a stationary autoregressive process of order $1, \operatorname{AR}(1)$. The latent process $\left\{h_{t}\right\}$ arises as an approximation to stochastic volatility diffusion of Hull and White (1987) and Chesney and Scott (1986) and, therefore, based on a well-developed theory. This latent process defined in Equation (2) is also more consistent with the unobserved volatility. Volatility is the result of flow of news into the markets and not directly observable. Thus, interpreting the latent volatility process $\left\{h_{t}\right\}$ as representing the random and uneven flow of new information is convenient, because it is very difficult, if not impossible, to model the information flow directly. This interpretation of the stochastic volatility model is proposed by Clark (1973) and Tauchen and Pitts (1983), which is more realistic than the observable conditional variance of the GARCH models as a measure of volatility. As shown by Taylor $(1986,1994)$, the SV models can be seen analogous of continues time option pricing models and, therefore, fit naturally well into the theoretical framework most of the finance theory has been developed.

The SV model has some features that makes them more attractive in modelling volatility dynamics compared to other models such the GARCH. The conditional volatility in GARCH models is perfectly and deterministically explained by the past observations, whereas the SV model allows additional uncertainty in the volatility by introducing stochastic shock term $\varepsilon_{t}^{h}$ in Equation (2). An important consequence of this feature of the SV models is the absence of any moment restriction requirements (see e.g. Meddahi and Renault 2004), which is an important requirement in the GARCH models and reduces their flexibility. The absence of moment restrictions in the SV models implies that they can have better in sample fit than the GARCH models and likely to give better forecasts unlike the GARCH models which are known with their poor out of sample forecasting performance (Danielsson 1994, Kim, Shephard and Chib 
1998). Although they look simple in their dynamic property with an AR(1) specifications, the SV models indeed are quite flexible in their capacity to model persistence in volatility. Granger and Newbold (1976) show that autocorrelations of the log volatility process $\left\{h_{t}\right\}$ implies an autoregressive moving average process for the square of $y_{t}$ with orders $(1,1)$, i.e. $\operatorname{ARMA}(1,1)$, and therefore can capture high persistence. Therefore, the AR(1) structure in Equation (1), when all components of the model is considered, is not restrictive in terms of volatility persistence and, indeed, more flexible than a GARCH(1,1) process (Davidian and Carroll 1987, Shephard 1996).

\section{Data}

In this study, the data we use consist of monthly US dollar closing prices of crude oil spot (Crude Oil-WTI Spot Cushing) and futures contracts traded on the New York Mercantile Exchange (NYM-Light Crude contracts 1 to 10) which are taken from Datastream. The sample period is not the same for each series because crude oil spot and futures contracts have begun their operations at different dates. Since all the price data are not stationary in the levels we transform the data into stationary series by taking first differences of the logarithmic prices and multiplying by 100 . Thus, the data used in the analysis is the log-returns $\left(r_{t}\right)$ defined as $r_{t}=$ $100 * \ln \left(p_{t} / p_{t-1}\right)$, where $p_{t}$ is the price at time $t$. The log-returns data are plotted in Figure 1 . The descriptive statistics for both the spot and futures returns included in the sample along with the beginning date are given in Table 1. The data span is from the date reported in the first row of Table 1 to 17 March 2017.

The use of monthly data was more appropriate in our case, given that we wished to characterize a dependence structure. Daily or high-frequency data may be affected by drifts and 
noise that could mask the dependence relationship and complicate modelling of the marginal distributions through non-stationary variances, long-memory or sudden jumps. Our results were insensitive to the choice of a daily or weekly frequency. Moreover, as the crude oil and future oil prices are highly volatile, it appears difficult to capture linkage between oil price and its volatility on a daily or weekly basis. Hence, we prefer to use the data at monthly frequency data rather than the daily frequency data. Before investigating the dynamic linkages between oil price and its volatility, we first apply the Augmented Dickey-Fuller (henceforth ADF) of Said and Dickey (1984) and the Phillip-Perron of Phillip and Perron (1988) (henceforth PP) unit root test to the oil spot and futures price series to determine whether they are stationary or not. The tests are conducted for the levels of the series as well as for the first differenced series. Our main finding is that the spot and futures oil and gold prices are integrated of order one. We also note that when considering the first differenced oil and futures prices, the unit root null is rejected. This confirms that the returns series for both gold and oil prices are stationary. ${ }^{4}$ Thus, we use the oil spot and futures return series calculated as the monthly percentage differences of the natural $\log$ of the oil spot and futures price series.

There is widespread concern that large fluctuations in the price of oil are harmful to the economies, particularly, of the oil importers. In addition, the volatility of the price of oil also poses challenges for policy makers in oil-exporting economies. Figure 1 provides the time series plot of oil spot and futures return for 1-month to 10-month contracts series. Figure 1 shows the percent deviation of the price of oil spot and futures return from its average value since early 1980. It is evident that the price of oil repeatedly has undergone large and persistent fluctuations that must have put stress on the global economy. Large sustained oil price returns increases occurred in particular in mid 1980s, in 1990/91, after 1999, between 2003 and late

\footnotetext{
${ }^{4}$ Complete details of the unit root tests are available upon request from the authors.
} 
(a) Spot

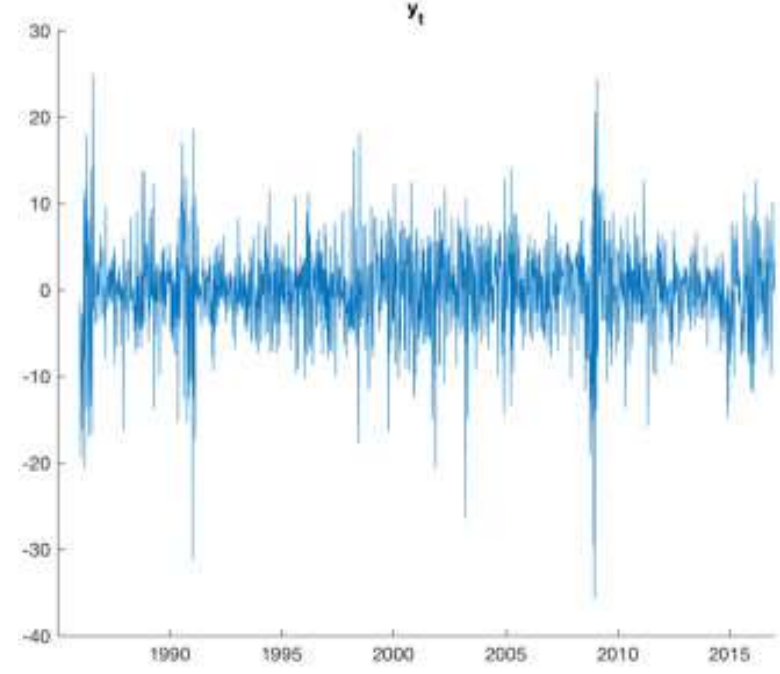

(c) 2-month

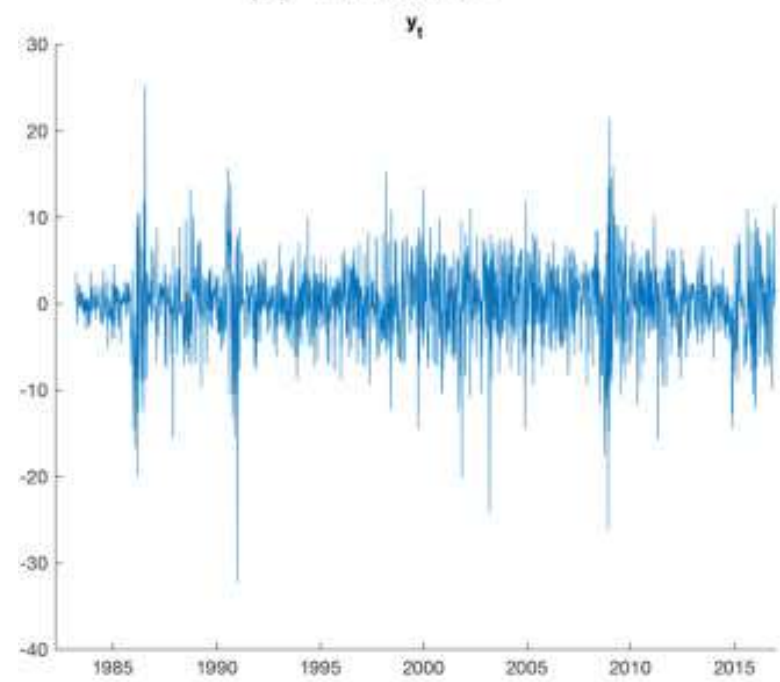

(e) 4-month

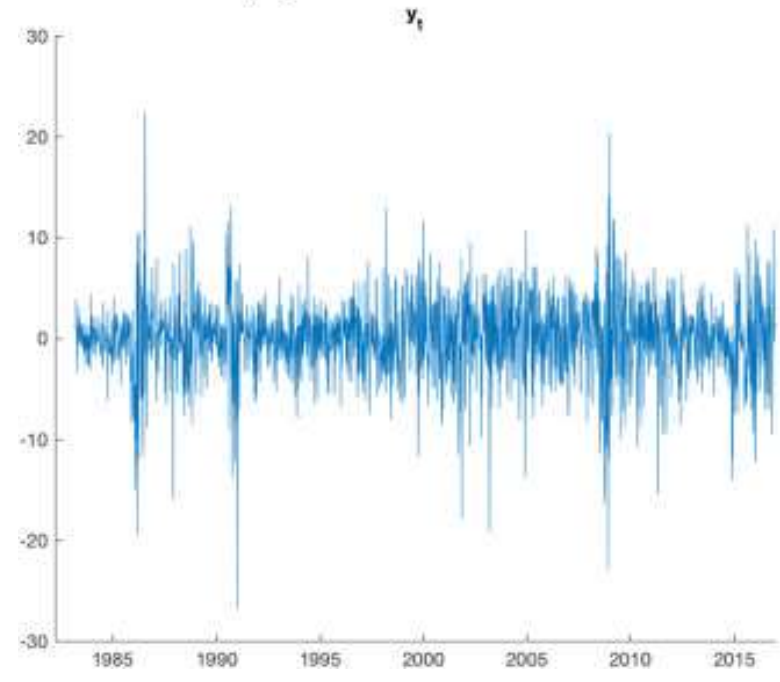

(b) 1-month

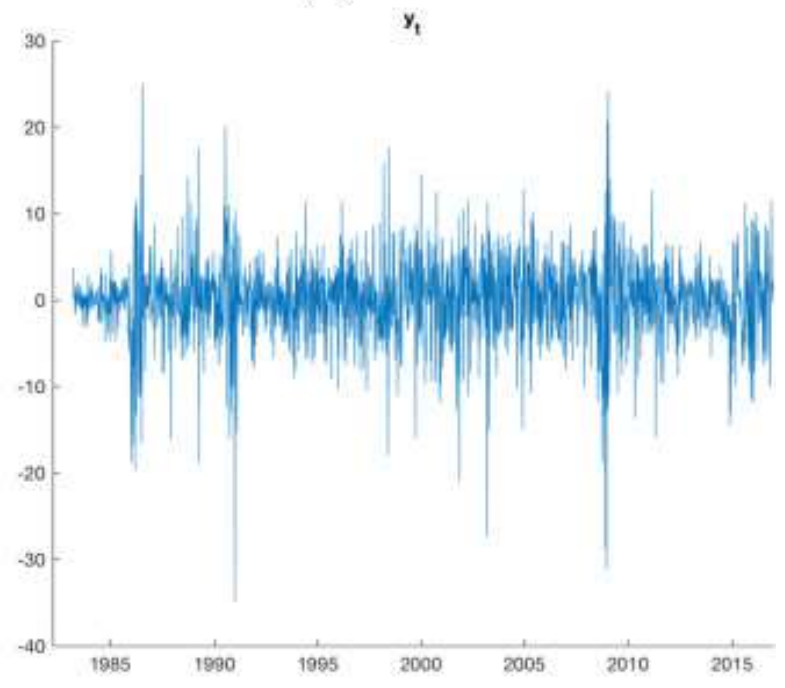

(d) 3-month

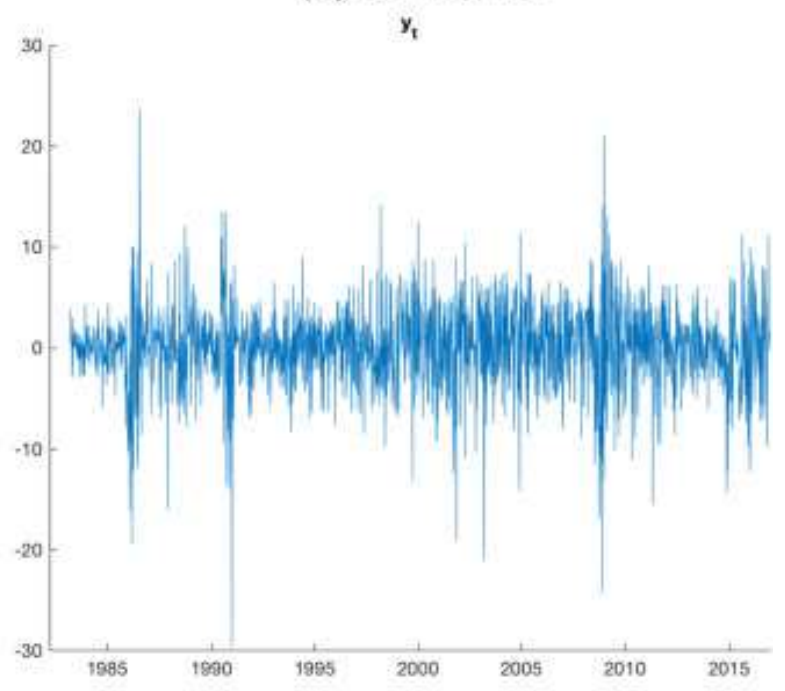

(f) 5-month

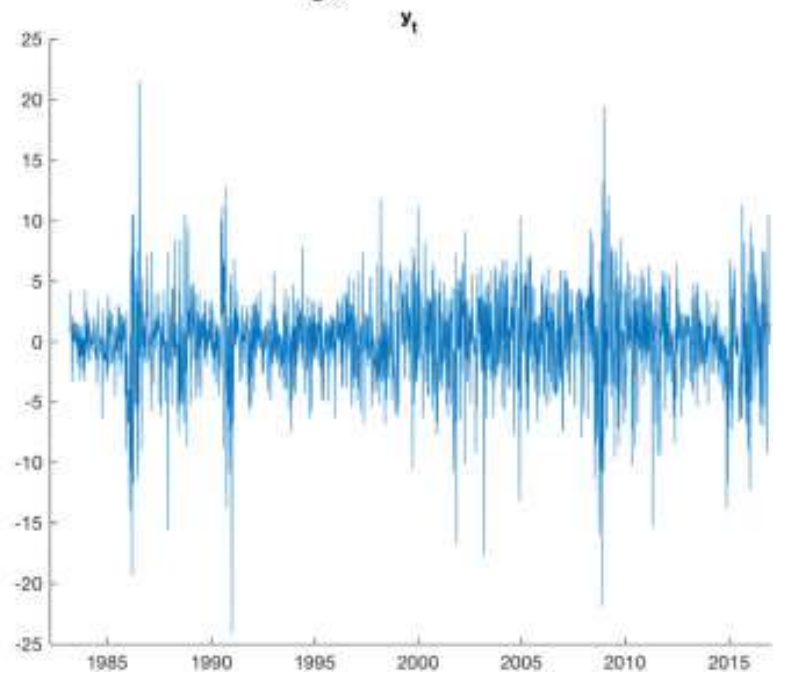


(g) 6-month

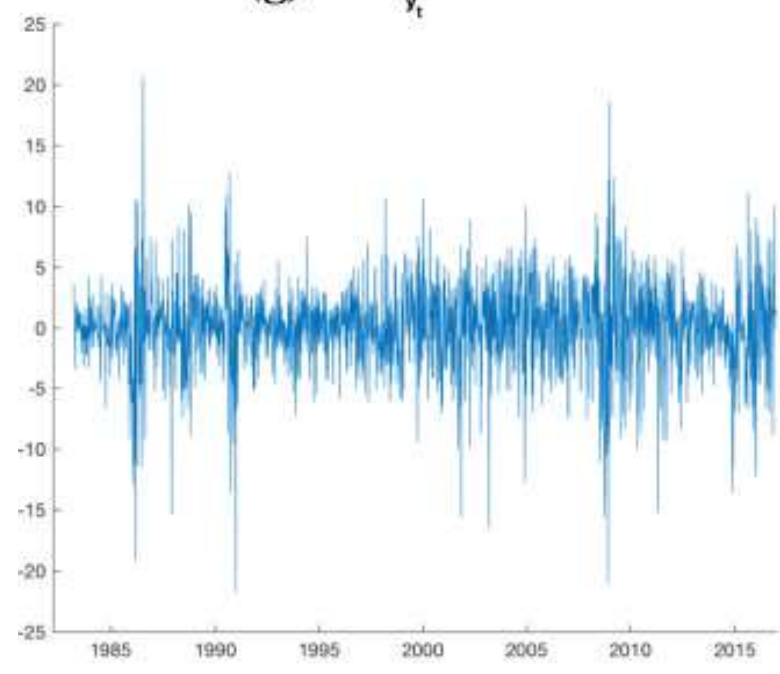

(i) 8-month

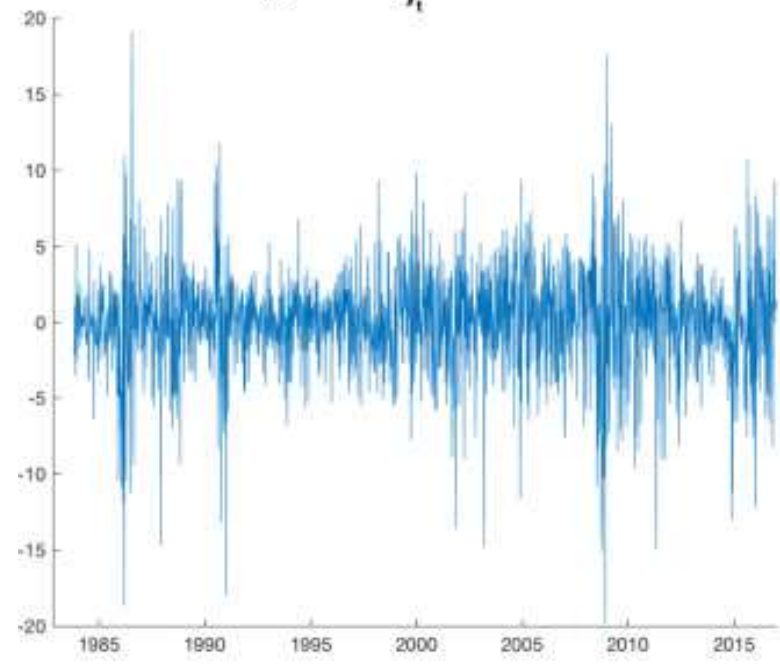

(h) $7-$ month

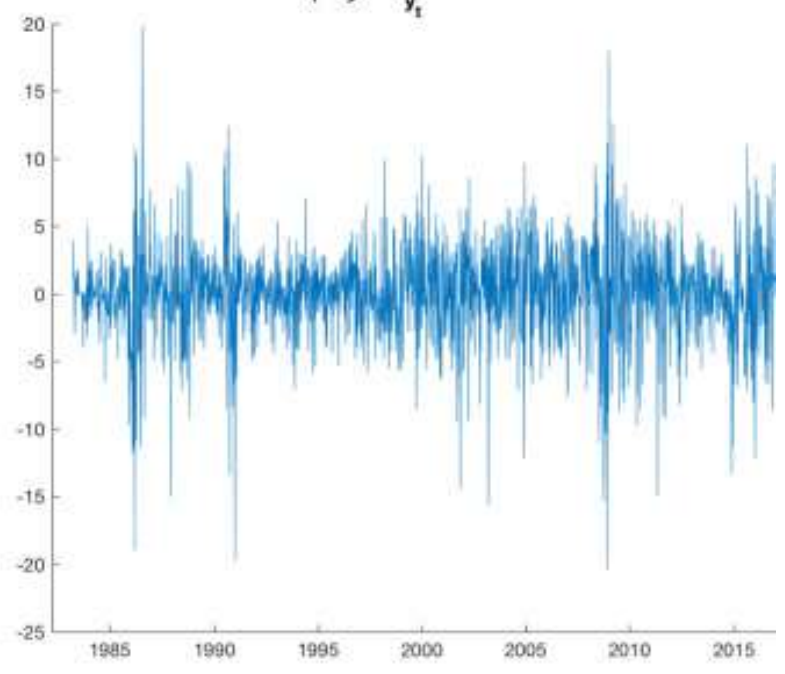

(j) 9-month

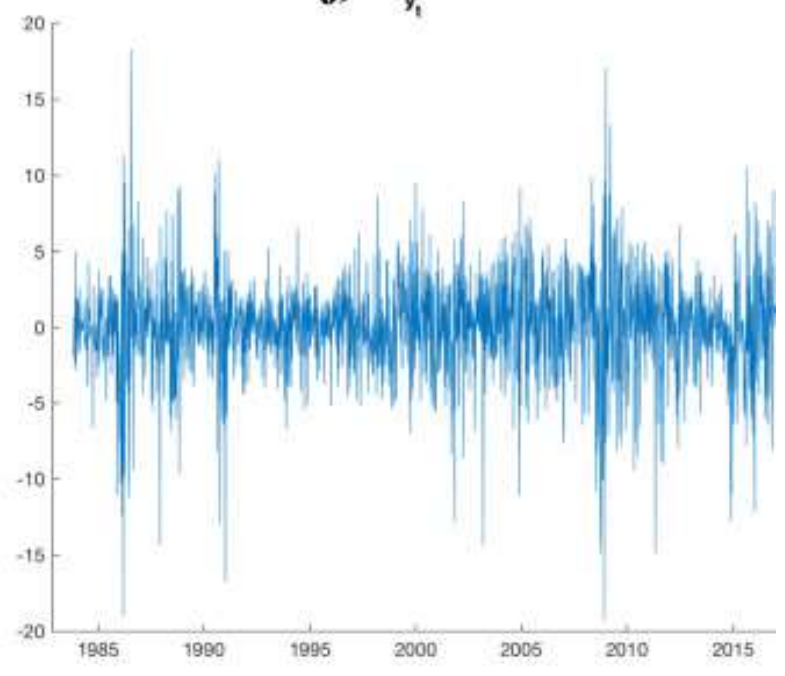

(k) 10-month

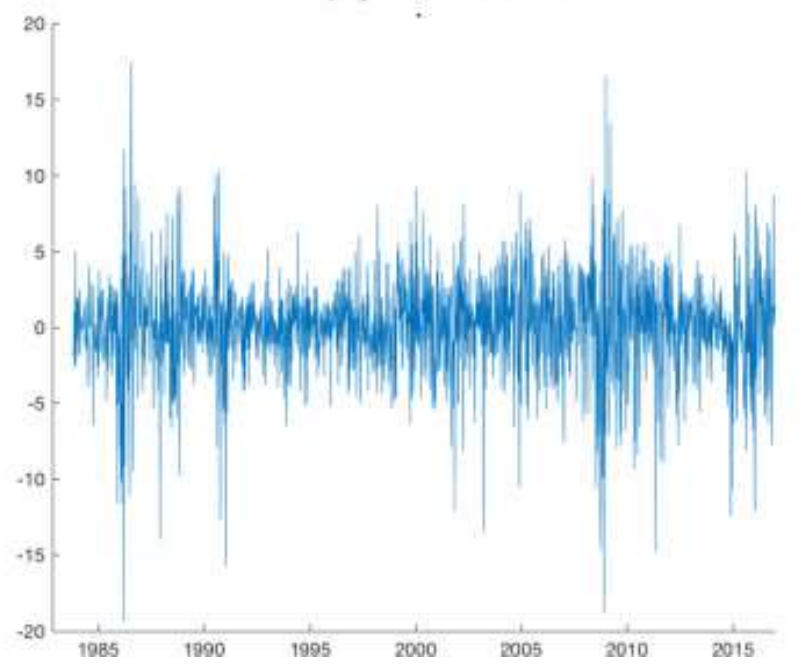

Fig. 1. Time Series plot of Spot and Futures Return Series. 
2008, in 2009/10, and starting in 2015. It can be observed that major sustained oil price returns declines occurred substantially in other sub-periods.

We first look at the descriptive statistics for the monthly oil spot and futures price return series in percent in Table 1. $n$ shows the number of observations for each series. In Table 1 , we report the mean, the standard deviation (S.D.), minimum (min), maximum (max), skewness, and kurtosis, the Jarque-Bera (JB) normality test (JB), the Ljung-Box first [Q(1)] and the fourth $[\mathrm{Q}(4)]$ autocorrelation tests, and the first $[\mathrm{ARCH}(1)]$ and the fourth $[\mathrm{ARCH}(4)]$ order Lagrange multiplier (LM) tests for the autoregressive conditional heteroskedasticity (ARCH). The mean of oil price returns shows that is it lowest for the oil futures price return for the all maturity contracts but gradually increases for spot prices, reaching an average price return of around 0.4 peent for the spot series. Secondly, we notice that the volatility of oil spot and futures markets measured by the S.D. at shorter maturities (for example, 1-month to 6-month maturities) is higher for compared to the longer maturities, that is, volatility decreases with maturity. Based on the negative values of the skewness, there is a higher possibility of large decreases in returns for oil spot and futures markets at all maturities. Based on the kurtosis statistic, we observe fattailed distribution for all return series. As a more important finding, the variables under consideration are skewed to left, with positive excess kurtosis, leading to non-normal distributions, as shown by the strong rejection of the JB statistic at $1 \%$ significance level. The statistics relating to skewness, Kurtosis, and JB all reveal that spot and futures prices are nonnormal. We observe significant serial correlation for spot and 1-month futures returns; while significant serial correlation is not found for oil futures markets at maturities greater than one month, as suggested by Ljung-Box statistic. There are ARCH effects in all the return series, as shown by the ARCH-Lagrange multiplier (ARCH-LM) statistic. 
Table 1. Descriptive Statistics

\begin{tabular}{|c|c|c|c|c|c|c|}
\hline & Spot & 1-month & 2-month & 3-month & 4-month & 5-month \\
\hline \multirow[t]{2}{*}{ Sample period } & 01/03/1986- & 04/08/1983- & 04/08/1983- & 04/08/1983- & 04/08/1983- & 04/08/1983- \\
\hline & $03 / 17 / 2017$ & $03 / 17 / 2017$ & $03 / 17 / 2017$ & $03 / 17 / 2017$ & $03 / 17 / 2017$ & $03 / 17 / 2017$ \\
\hline$n$ & 1628 & 1772 & 1772 & 1772 & 1772 & 1772 \\
\hline Mean & 0.04 & 0.03 & 0.03 & 0.03 & 0.03 & 0.03 \\
\hline S.D. & 5.29 & 4.95 & 4.51 & 4.22 & 4.00 & 3.83 \\
\hline Min & -35.73 & -34.90 & -32.34 & -29.56 & -26.82 & -24.10 \\
\hline $\operatorname{Max}$ & 24.93 & 25.00 & 25.26 & 23.67 & 22.33 & 21.51 \\
\hline Skewness & -0.62 & -0.66 & -0.56 & -0.57 & -0.56 & -0.54 \\
\hline Kurtosis & 4.27 & 5.09 & 4.32 & 4.21 & 4.11 & 4.00 \\
\hline JB & $1347.83^{* * * *}$ & $2045.28^{* * *}$ & $1473.94^{* * *}$ & $1407.81^{* * *}$ & $1346.39^{* * *}$ & $1272.73^{* * *}$ \\
\hline $\mathrm{Q}(1)$ & $10.70^{* * *}$ & $4.46^{\text {** }}$ & 1.16 & 0.56 & 0.48 & 0.48 \\
\hline $\mathrm{Q}(4)$ & $16.96^{* * *}$ & $11.53^{* *}$ & $8.29^{*}$ & $8.00^{*}$ & $8.43^{*}$ & $9.17^{*}$ \\
\hline $\mathrm{ARCH}(1)$ & $96.74^{* * *}$ & $63.32^{* * *}$ & $45.76^{* * *}$ & $47.70^{* * *}$ & $53.97^{* * *}$ & $59.10^{* * *}$ \\
\hline \multirow[t]{2}{*}{$\mathrm{ARCH}(4)$} & $248.75^{* * * *}$ & $182.95^{* * *}$ & $123.16^{* * *}$ & $123.66^{\text {**** }}$ & $134.16^{\text {*** }}$ & $143.66^{\text {*** }}$ \\
\hline & 6-month & 7-month & 8-month & 9-month & 10-month & \\
\hline \multirow[t]{2}{*}{ Sample period } & 04/08/1983- & 04/08/1983- & 11/11/1983- & 11/11/1983- & 11/11/1983- & \\
\hline & $03 / 17 / 2017$ & $03 / 17 / 2017$ & $03 / 17 / 2017$ & $03 / 17 / 2017$ & $03 / 17 / 2017$ & \\
\hline$n$ & 1772 & 1772 & 1740 & 1740 & 1740 & \\
\hline Mean & 0.03 & 0.03 & 0.03 & 0.03 & 0.03 & \\
\hline S.D. & 3.69 & 3.57 & 3.49 & 3.41 & 3.34 & \\
\hline Min & -21.76 & -20.37 & -19.82 & -19.31 & -19.36 & \\
\hline Max & 20.68 & 19.87 & 19.05 & 18.25 & 17.44 & \\
\hline Skewness & -0.53 & -0.51 & -0.51 & -0.52 & -0.51 & \\
\hline Kurtosis & 3.89 & 3.84 & 3.71 & 3.75 & 3.78 & \\
\hline JB & $1202.04^{* * * *}$ & $1169.10^{* * *}$ & $1074.10^{* * * *}$ & $1101.68^{* * *}$ & $1115.69^{* * *}$ & \\
\hline $\mathrm{Q}(1)$ & 0.55 & 0.73 & 1.08 & 1.55 & 1.78 & \\
\hline $\mathrm{Q}(4)$ & $9.27^{*}$ & $9.52^{* *}$ & $9.79^{* *}$ & $10.37^{* *}$ & $9.99^{* *}$ & \\
\hline $\mathrm{ARCH}(1)$ & $61.69^{* * *}$ & $64.52^{* * *}$ & $64.73^{* * *}$ & $67.06^{* * *}$ & $69.79^{* * *}$ & \\
\hline $\mathrm{ARCH}(4)$ & $151.33^{* * *}$ & $158.70^{* * *}$ & $158.75^{* * *}$ & $161.96^{\text {*** }}$ & $159.33^{\text {*** }}$ & \\
\hline
\end{tabular}

Note: Table reports the descriptive statistics for the monthly oil return series in percent. $n$ donates the number of observations for each series. In addition to the mean, the standard deviation (S.D.), minimum (min), maximum (max), skewness, and kurtosis statistics, the table reports the Jarque-Bera normality test (JB), the Ljung-Box first $[Q(1)]$ and the fourth $[Q(4)]$ autocorrelation tests, and the first $[\mathrm{ARCH}(1)]$ and the fourth $[\mathrm{ARCH}(4)]$ order Lagrange multiplier (LM) tests for the autoregressive conditional heteroskedasticity (ARCH). ${ }^{* * *},{ }^{* *}$, and ${ }^{*}$ represent significance at the $1 \%, 5 \%$, and $10 \%$ level, respectively.

\section{Analysis of the TVP-SVM empirical results}

In order to examine the dynamic linkages between oil price and its uncertainty, we first estimate the time-varying parameter stochastic volatility in mean (TVP-SVM) model for oil spot and futures return for 1-month to 10-month contracts series. The posterior moments and quantiles of the model parameters are reported in Table 2. The estimates associated with the parameters in the $\operatorname{AR}(1)$ process of $h_{t}$ are similar for all series we considered in the study. Such as, the transition of $h_{t}$ is highly persistent, with the posterior mean of $\phi$ estimated to be about 0.95 to 0.97 with a $90 \%$ credible interval $(0.928,0.995)$. Estimation results for $\beta$, the coefficient associated with the lagged oil price return, reported in Table 2 indicate that the impact of the 
lagged oil price return on oil price return uncertainty is quite small and negative. Its $90 \%$ credible confidence interval does not include 0 . This indicates that oil price has a negatively small negative impact on its volatility.

Table 2. Estimated Posterior Moments and Quantiles of the SV in Mean Model Parameters

\begin{tabular}{|c|c|c|c|c|c|c|c|}
\hline \multicolumn{4}{|c|}{ Spot } & \multicolumn{4}{|c|}{ 1-month } \\
\hline Parameter & Posterior mean & Standard error & $90 \%$ credible interval & Parameter & Posterior mean & Standard error & $\begin{array}{r}90 \% \text { credible interval } \\
(2.500,2.899)\end{array}$ \\
\hline $\begin{array}{l}\mu \\
\beta\end{array}$ & $\begin{array}{r}2.970 \\
-0.024\end{array}$ & $\begin{array}{l}0.094 \\
0.002\end{array}$ & $(-0.028,-0.020)$ & $\begin{array}{l}\mu \\
\beta\end{array}$ & -0.027 & 0.003 & $(-0.031,-0.022)$ \\
\hline$\phi$ & 0.959 & 0.007 & $(0.946,0.971)$ & $\phi$ & 0.968 & 0.006 & $(0.958,0.977)$ \\
\hline$\sigma^{2}$ & 0.017 & 0.003 & $(0.013,0.022)$ & $\sigma^{2}$ & 0.022 & 0.004 & $(0.017,0.029)$ \\
\hline$\omega_{\alpha}^{2}$ & 0.002 & 0.000 & $(0.002,0.003)$ & $\omega_{\alpha}^{2}$ & 0.003 & 0.001 & $(0.002,0.004)$ \\
\hline$\omega_{\alpha, \tau}^{2}$ & -0.002 & 0.001 & $(-0.004,0.000)$ & $\omega_{\alpha, \tau}^{2}$ & -0.003 & 0.002 & $(-0.006,0.000)$ \\
\hline$\omega_{\tau}^{2}$ & 0.056 & 0.017 & $(0.033,0.086)$ & $\omega_{\tau}^{2}$ & 0.065 & 0.022 & $(0.036,0.106)$ \\
\hline \multicolumn{4}{|c|}{ 2-month } & \multicolumn{4}{|c|}{ 3-month } \\
\hline$\mu$ & 2.551 & 0.111 & $(2.370,2.739)$ & $\mu$ & 2.427 & 0.111 & $(2.234,2.595)$ \\
\hline$\beta$ & -0.028 & 0.003 & $(-0.032,-0.024)$ & $\beta$ & -0.028 & 0.003 & $(-0.033,-0.024)$ \\
\hline$\phi$ & 0.968 & 0.006 & $(0.958,0.977)$ & $\phi$ & 0.968 & 0.006 & $(0.958,0.977)$ \\
\hline$\sigma^{2}$ & 0.020 & 0.003 & $(0.015,0.025)$ & $\sigma^{2}$ & 0.019 & 0.003 & $(0.015,0.025)$ \\
\hline$\omega_{\alpha}^{2}$ & 0.003 & 0.001 & $(0.002,0.004)$ & $\omega_{\alpha}^{2}$ & 0.003 & 0.001 & $(0.002,0.004)$ \\
\hline$\omega_{\alpha, \tau}^{2}$ & -0.003 & 0.002 & $(-0.007,0.000)$ & $\omega_{\alpha, \tau}^{2}$ & -0.003 & 0.002 & $(-0.007,0.000)$ \\
\hline$\omega_{\tau}^{2,}$ & 0.060 & 0.019 & $(0.036,0.093)$ & $\omega_{\tau}^{2,}$ & 0.060 & 0.018 & $(0.035,0.096)$ \\
\hline \multicolumn{4}{|c|}{ 4-month } & \multicolumn{4}{|c|}{ 5-month } \\
\hline$\mu$ & 2.327 & 0.118 & $(2.133,2.519)$ & $\mu$ & 2.231 & 0.121 & $(2.033,2.427)$ \\
\hline$\beta$ & -0.029 & 0.003 & $(-0.034,-0.024)$ & $\beta$ & -0.029 & 0.003 & $(-0.035,-0.024)$ \\
\hline$\phi$ & 0.969 & 0.006 & $(0.959,0.978)$ & $\phi$ & 0.970 & 0.006 & $(0.960,0.980)$ \\
\hline$\sigma^{2}$ & 0.020 & 0.003 & $(0.015,0.025)$ & $\sigma^{2}$ & 0.020 & 0.003 & $(0.015,0.025)$ \\
\hline$\omega_{\alpha}^{2}$ & 0.003 & 0.001 & $(0.002,0.004)$ & $\omega_{\alpha}^{2}$ & 0.003 & 0.001 & $(0.002,0.005)$ \\
\hline$\omega_{\alpha, \tau}^{2}$ & -0.003 & 0.002 & $(-0.007,0.000)$ & $\omega_{\alpha, \tau}^{2}$ & -0.004 & 0.002 & $(-0.008,-0.000)$ \\
\hline$\omega_{\tau}^{2}$ & 0.053 & 0.016 & $(0.034,0.085)$ & $\omega_{\tau}^{2}$ & 0.055 & 0.020 & $(0.033,0.093)$ \\
\hline \multicolumn{4}{|c|}{ 6-month } & \multicolumn{4}{|c|}{ 7-month } \\
\hline$\mu$ & 2.165 & 0.121 & $(1.968,2.359)$ & $\mu$ & 2.089 & 0.125 & $(1.885,2.284)$ \\
\hline$\beta$ & -0.030 & 0.003 & $(-0.035,-0.025)$ & $\beta$ & -0.031 & 0.004 & $(-0.037,-0.025)$ \\
\hline$\phi$ & 0.970 & 0.006 & $(0.960,0.980)$ & $\phi$ & 0.970 & 0.006 & $(0.960,0.979)$ \\
\hline$\sigma^{2}$ & 0.020 & 0.003 & $(0.015,0.026)$ & $\sigma^{2}$ & 0.021 & 0.003 & $(0.016,0.027)$ \\
\hline$\omega_{\alpha}^{2}$ & 0.003 & 0.001 & $(0.002,0.005)$ & $\omega_{\alpha}^{2}$ & 0.003 & 0.001 & $(0.002,0.004)$ \\
\hline$\omega_{\alpha, \tau}^{2}$ & -0.003 & 0.003 & $(-0.008,0.000)$ & $\omega_{\alpha, \tau}^{2}$ & -0.003 & 0.002 & $(-0.006,-0.000)$ \\
\hline$\omega_{\tau}^{2, \imath}$ & 0.051 & 0.016 & $(0.030,0.083)$ & $\omega_{\tau}^{2}$ & 0.047 & 0.015 & $(0.028,0.077)$ \\
\hline \multicolumn{4}{|c|}{ 8-month } & \multicolumn{4}{|c|}{ 9-month } \\
\hline$\mu$ & 2.071 & 0.127 & $(1.865,2.283)$ & $\mu$ & 2.020 & 0.129 & $(1.808,2.226)$ \\
\hline$\beta$ & -0.030 & 0.004 & $(-0.037,-0.024)$ & $\beta$ & -0.030 & 0.004 & $(-0.037,-0.023)$ \\
\hline$\phi$ & 0.970 & 0.007 & $(0.958,0.980)$ & $\phi$ & 0.970 & 0.006 & $(0.960,0.980)$ \\
\hline$\sigma^{2}$ & 0.021 & 0.003 & $(0.016,0.027)$ & $\sigma^{2}$ & 0.021 & 0.003 & $(0.017,0.028)$ \\
\hline$\omega_{\alpha}^{2}$ & 0.003 & 0.001 & $(0.002,0.005)$ & $\omega_{\alpha}^{2}$ & 0.003 & 0.001 & $(0.002,0.004)$ \\
\hline$\omega_{\alpha, \tau}^{2}$ & -0.004 & 0.002 & $(-0.008,-0.000)$ & $\omega_{\alpha, \tau}^{2}$ & -0.003 & 0.002 & $(-0.008,-0.000)$ \\
\hline$\omega_{\tau}^{2}$ & 0.048 & 0.014 & $(0.031,0.074)$ & $\omega_{\tau}^{2}$ & 0.046 & 0.015 & $(0.026,0.072)$ \\
\hline \multicolumn{4}{|c|}{ 10-month } & & & & \\
\hline$\mu$ & 1.972 & 0.132 & $(1.751,2.172)$ & & & & \\
\hline$\beta$ & -0.031 & 0.005 & $(-0.038,-0.022)$ & & & & \\
\hline$\phi$ & 0.970 & 0.006 & $(0.960,0.981)$ & & & & \\
\hline$\sigma^{2}$ & 0.022 & 0.004 & $(0.016,0.029)$ & & & & \\
\hline$\omega_{\alpha}^{2}$ & 0.003 & 0.001 & $(0.002,0.004)$ & & & & \\
\hline$\omega_{\alpha, \tau}^{2}$ & -0.003 & 0.002 & $(-0.006,-0.000)$ & & & & \\
\hline$\omega_{\tau}^{2, l}$ & 0.043 & 0.010 & $(0.028,0.061)$ & & & & \\
\hline
\end{tabular}

Note: The results are based on 50,000 posterior with a burn-in period of 50,000. 

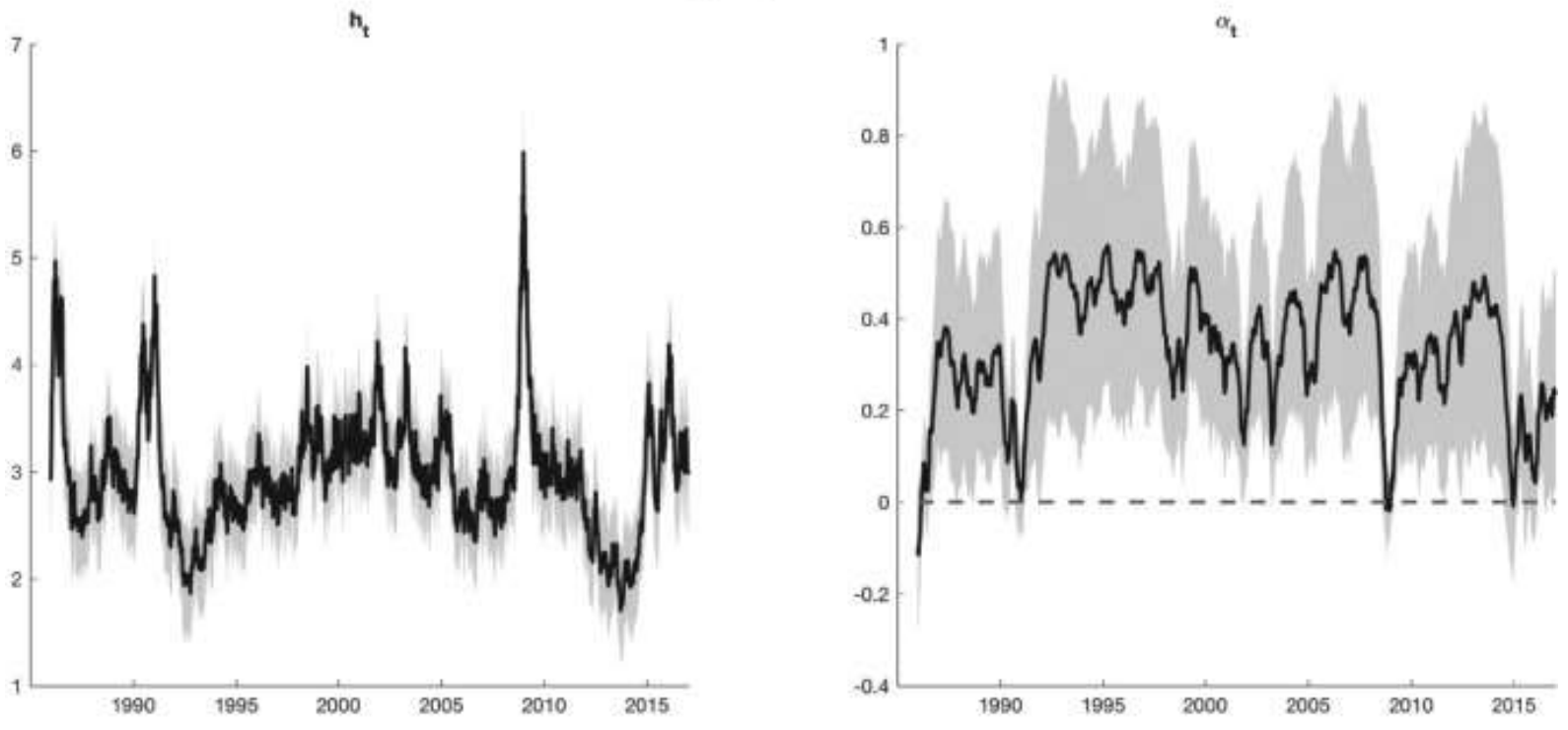

(b) 1-month
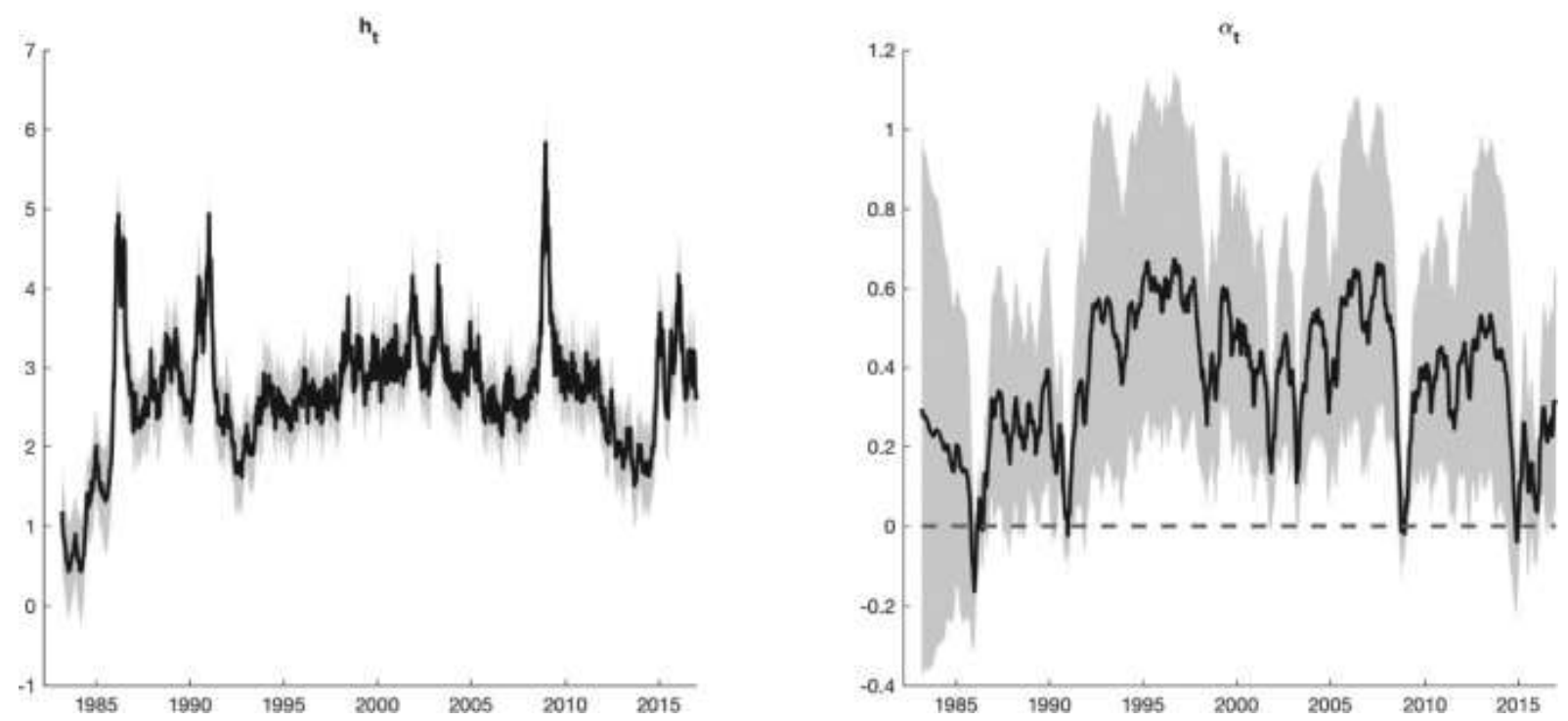

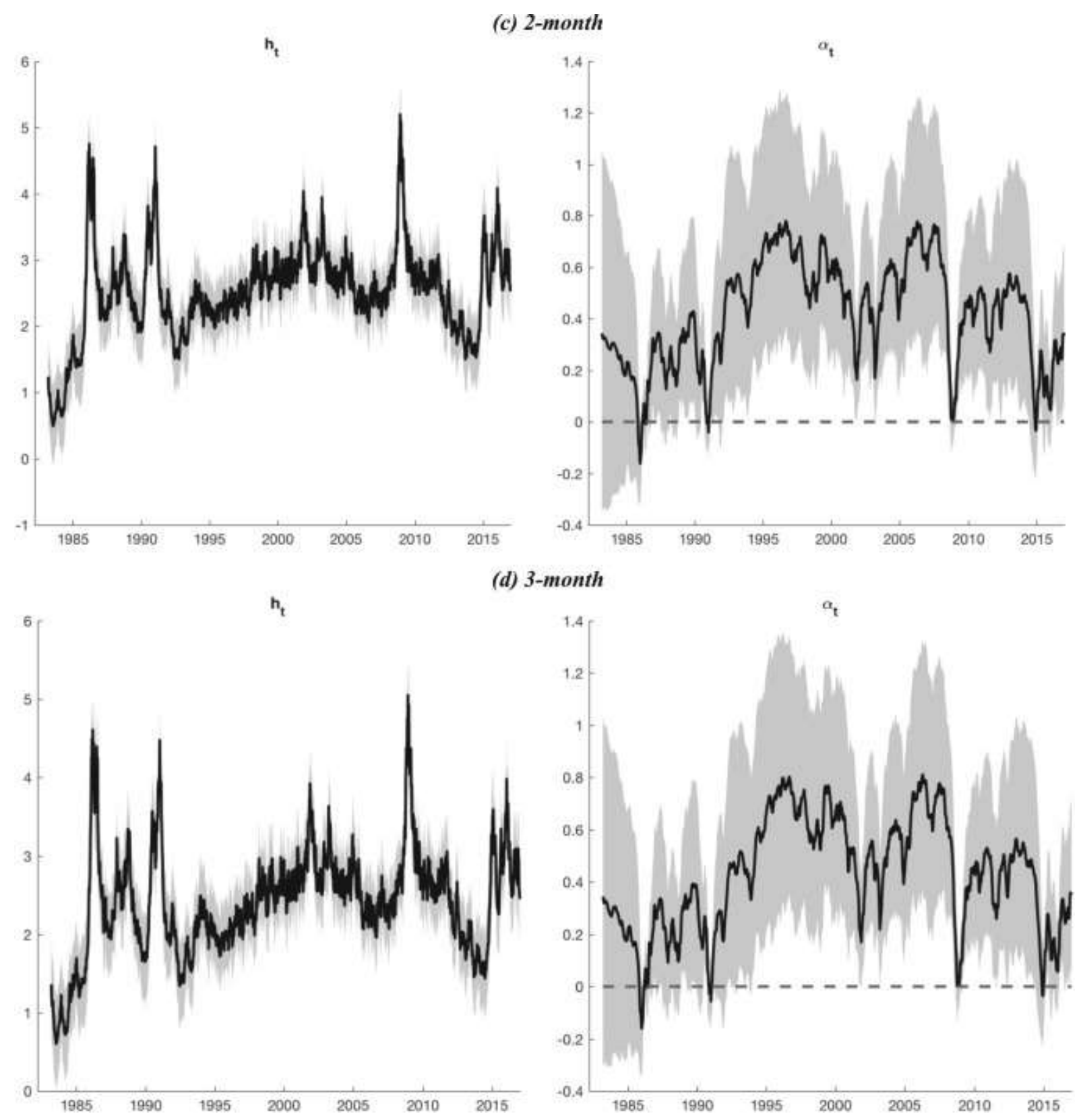

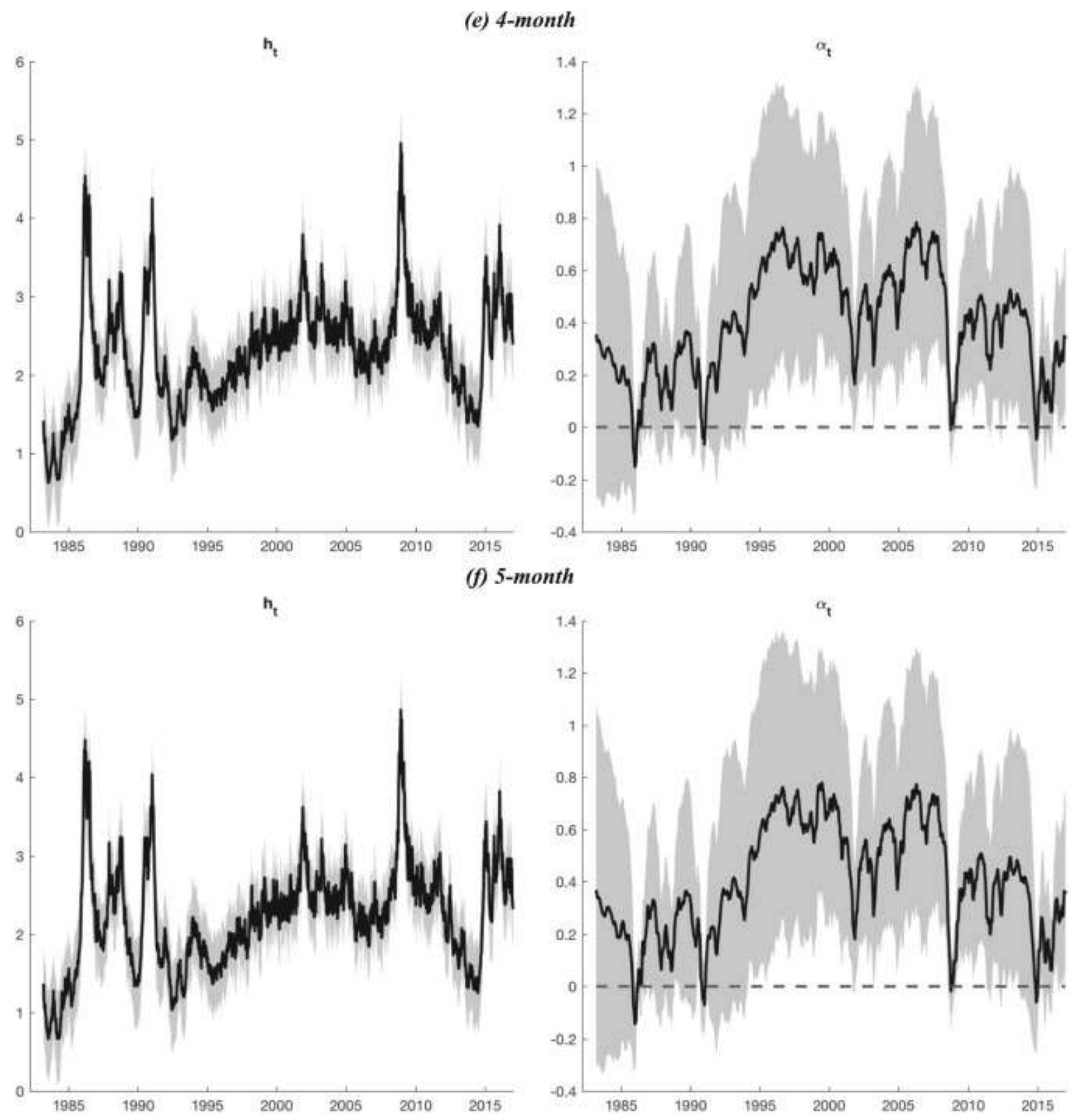


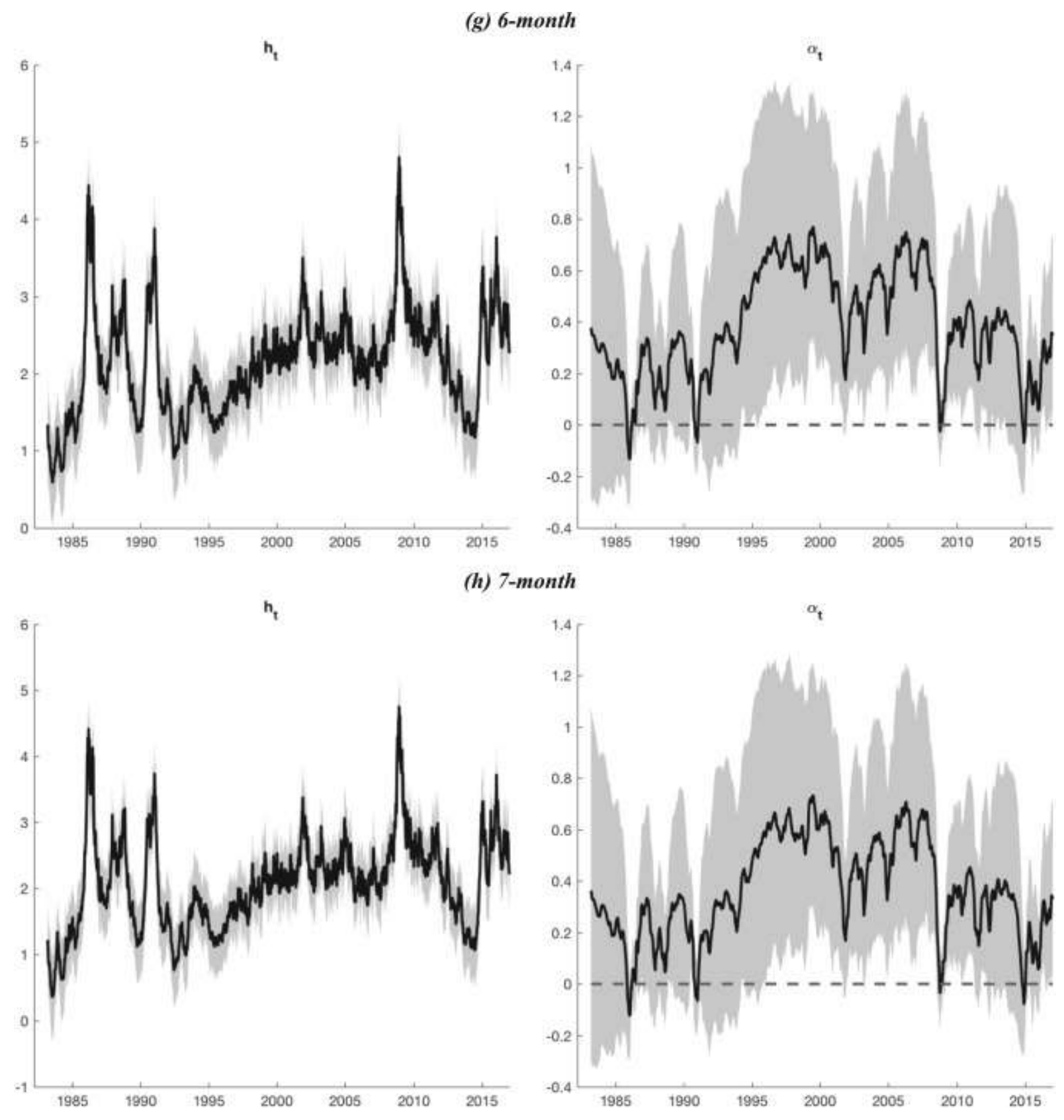




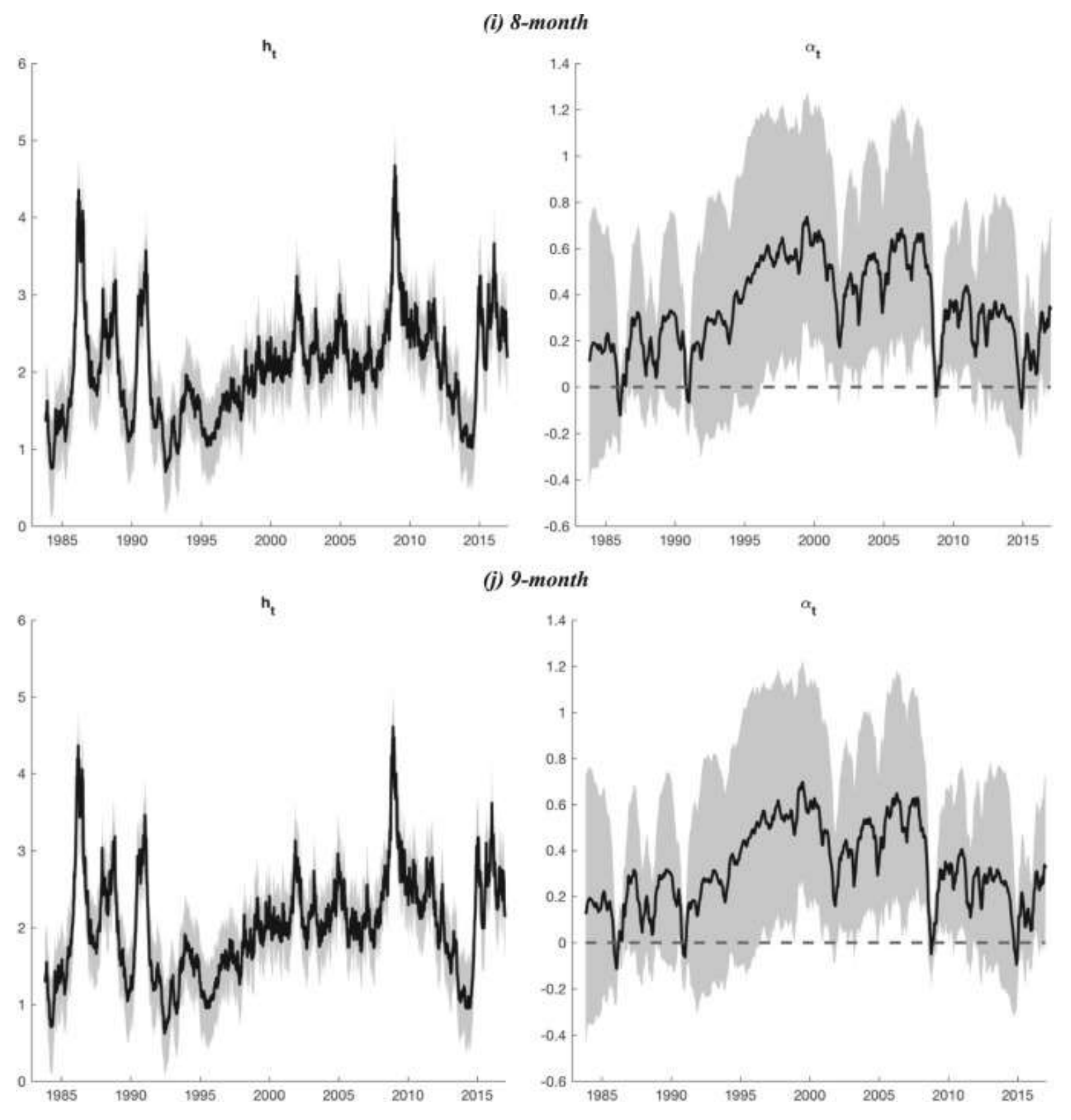



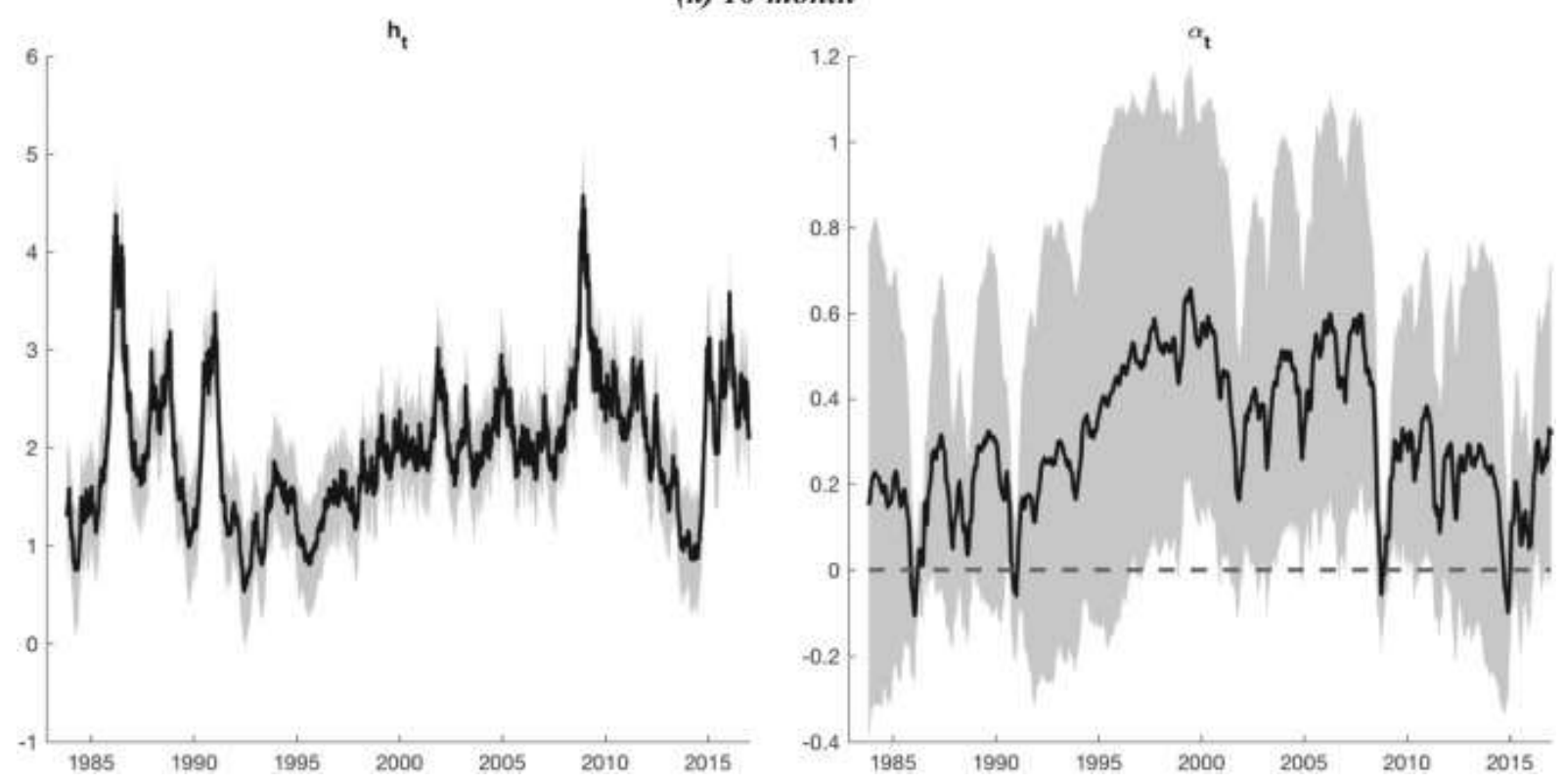

Note: The figure plots the evolution of the return volatility $h_{t}$ (left panel) and time-varying impact of the return volatility on return growth $\alpha_{t}$ (right panel). The solid lines are the estimated posterior means and the shaded regions denote the $90 \%$ credible confidence intervals. The results are based on 50,000 posterior with a burn-in period of 50,000 .

Figures 2 plot the estimation results of the oil price return volatility $\left(h_{t}\right)$ and its timevarying impact $\left(\alpha_{t}\right)$ on oil price return for the crude oil spot and futures markets for 1-month to 10-month maturities, respectively, as well as the associated $90 \%$ credible confidence intervals. The left panel of the Figure 2 reports the estimates of $h_{t}$. The estimates of $h_{t}$ typically show high volatility and are analogues for all series. For example, the oil price return volatility increases substantially during the mid-1990s-early-2010s period and subsides during the others, until it peaks before early 1990s and following the aftermath of the Global Financial Crisis. In the aftermath of Global Financial Crisis, the crude and future oil price return volatility declined starting from the peak level reached in 2008. Then, it increases starting from the mid-2015s. The right panel of the Figure 2 reports the estimates of $\alpha_{t}$. The shaded (in grey colour) regions around the time-varying impact of oil price return volatility on oil price return $\left(\alpha_{t}\right)$ lines represent the $90 \%$ confidence intervals. The estimation results of the $90 \%$ confidence intervals are based on 50,000 posterior with a burn-in period of 50,000. Estimation results of $\alpha_{t}$ for each 
series indicate substantial time-variation in the impact of uncertainty on oil price, highlighting the importance of the time-varying parameter extension in our study.

On examining the estimation results of $\alpha_{t}$ for crude oil spot and futures markets, it was found that they spot market and futures market estimates were moving in reverse direction for until the early 1990s, but they move in the same direction after early 1990s. Estimation results for crude oil spot serious are shown in panel (a) in Figure 2. The estimations for $\alpha_{t}$ are positive in almost all periods except for a few short periods. Moreover, the estimates are mostly between 0.1 and 0.9 , whereas they become much smaller and even negative in 2008 before turning positive again in early 2010s. The results given in right panel of Figure 2 show that the uncertainty of crude oil spot price return series measured by the stochastic volatility has a positive impact on the crude oil spot price return series over the entire sample period with the expectation of four short sub-periods where the impact is close to zero or even negative. As mention before, the results for spot markets and future markets differ slightly. The difference is particularly observed in the period between the mid-1980s and the early 1990s. Although minor differences are observed in some periods after the early 1990s, it may be said that the results are quite analogues in general for spot and futures markets. An analysis of the $\alpha_{t}$ estimation results demonstrates that estimation results are almost analogues in terms of their magnitudes and fluctuations. Moreover, there is apparent and substantial time-variation in the estimates both for the spot and futures markets, highlighting the importance of the time-varying parameter extension. Estimates of $\alpha_{t}$ decline significantly and even become negative twice before mid-1990 and twice after the Global Financial Crisis. The estimates before mid-1990 mostly vary between 0 and 0.4 , but they become negative in two sub-periods, namely in 1986 and 1991. The evidence from right panel of Figure 2 for futures markets for 1-month to 10month maturities show that the future oil price return uncertainty - measured by the stochastic 
volatility - has positive but insignificant impact on the future oil price return from the beginning of the sample till mid-1990s and from the aftermath of the Global Financial Crisis to till the ending of the sample except for one sub-period. The exception sub-period starts in mid-1990sand extents until the start of the Global Financial Crisis in which the future oil price return uncertainty has a positive and significant impact on the future oil price series. An important observation from the estimates given in Figure 2 is the association between the negative estimates of $\alpha_{t}$ and the large positive volatility shocks. We observe that oil price volatility has large positive shocks in periods corresponding to collapse of OPEC in 1986, invasion of Kuwait in 1990/91, Asian crisis in 1997/2000 and the Global Financial Crisis in 2008. Salisu and Fasanya (2013) also found structural breaks in the oil price volatility in 1990 and 2008 using volatility structural break tests. Estimates of the impact of uncertainty on oil price turn negative during these large positive shock periods, indicating that oil price hikes in these periods are reversed. This can be interpreted as the sign of the start of a declining trend in oil prices following the price hikes. The literature on financial markets finds a similar behaviour in stock markets where market crashes follow large volatility shocks.

Compared to the previous literature, one of the most important findings in our study is the substantial time variation in the impact of the uncertainty on oil prices. Indeed, the coefficient measuring the effect of the uncertainty has several significant structural breaks with sign turning from positive to negative. This time variation needs to be examined closely. In the recent years, the researchers increasingly emphasised the importance of shifts in the demand for oil and provided evidence that oil demand shocks have been important cause of major crude oil price shock incidences since the 1970s. As reported in the literature (see, e.g., Kilian, 2010; Baumeister and Kilian, 2016a,b), while shocks to the flow supply of crude oil did not influence the price of oil since 1973, shocks to the flow demand for oil which results from the global 
business cycles have been accountable for the major changes in the price of oil such as those in 1979-1980 and 2003-2008. Further, the speculative demand shocks which mirror the forward looking behaviour by traders have been influential on oil price fluctuations. These demand shocks included the episodes following the Iranian Revolution in 1979, collapse of OPEC in 1986, invasion of Kuwait in 1990/91, Asian crisis in 1997/2000 and the Global Financial Crisis in 2008. The main characteristic of the speculative demand shocks is that it can result in large and instant impact on the price of oil (Kilian, 2010; Baumeister and Kilian, 2016a,b). Due to these demand driven dynamics in the oil market, uncertainty about the future path of the crude oil prices may results in chances in the crude oil price. A speculative demand shock which results in large and instant effects on the price of oil is generated by the expectations. The news about future oil demand or oil supply may cause a jumps in the oil price. An example would be as follows. The demand for crude oil by inventories in the current period will increase ceteris paribus as a result of a downward revision to expected future supply of crude oil or upward revision to expected future demand for crude oil. This will cause an immediate shift in the current demand curve along the supply curve with the end result of an increase in the price of oil (Kilian, 2010; Baumeister and Kilian, 2016a,b).

Considering the last quarter of the century, oil prices have fallen globally in the 1990s. Following the 1997 Asian Crisis, oil prices dropped to the level of 12 US dollars per barrel, and they began to rise again by the end of 1990s with the reduction of oil supply by Russia and OPEC countries. The policy of decreasing oil production was implemented against low oil prices in 2002. Oil prices were on rapid rise on international markets beginning with 2003 until 2008. This may be regarded as the joint consequence of increasing oil demand in parallel to the rapid growth in world economy and of speculative factors. After Global Financial Crisis experienced in 2008, the oil price which was declining to the level of 60 US dollars began to 
rise again due to global growth trend in the following years and due to probable expectation of reduction in oil supply with Arab Spring. Thus, the prices escalating to 160 US dollars on world markets have been above 100 US dollars since 2010 (for the last four years) (OPEC, 2014). This trend of rise in oil prices changed into a falling trend in June 2014, and it has been at the level of 50 US dollars since early 2015. On examining all these developments in oil markets and the results we have obtained in this study, we conclude that our results well capture the effects of historical developments and quite rich.

\section{Conclusion}

The price of oil is one of the key global macroeconomic variables that is constantly monitored by the administrators of almost all firms, investors, governments, and policy makers. The impact of the oil price on the growth performance of all world economics has been long recognised by the economists. Oil price hikes have been considered as the prime cause of several global recessions, the most influential one being the $1973-74$ oil price shock. The most advanced economies of the world have experienced a slower growth trend for a decade or longer in the aftermath of the 1973-74 oil price shock. Thus, the expectation on the oil price is a key element in the decisions making of all economic agents. Uncertainty is the key variable in decisions concerning the future. As most economic decisions linked to expectations for the future involves oil prices, uncertainty of the oil prices play a very significant role in the decision making of all agent. This study examines the dynamic interaction between the oil price and its uncertainty in a model that optimally accounts for the turbulent history of oil markets.

The previous literature analysing the effects of oil price on basic macroeconomic variables or the effects of oil price volatility on both oil price and basic macroeconomic 
variables volatility is specified as a GARCH model, where the volatility is deterministic. The SV model used in this study, on the other hand, considers uncertainty with a volatility specification that allows stochastic volatility shocks. Hence, the SV model does not impose restrictions on conditional moments, while the GARCH model does, as stated by Meddahi and Renault (2004). We additionally specify the impact of uncertainty as time-varying in order to account for the effect of structural breaks. Our study contributes to the existing literature on oil markets in two important ways. First, using the time-varying parameter stochastic volatility in the mean model, we contribute to the existing literature by allowing time-varying impact of oil price uncertainty on oil price. Second, we estimate a more realistic oil price uncertainty and risk by using the stochastic volatility model, which allows volatility shocks whereas commonly used GARCH models in the literature have a deterministic volatility specification.

Our findings are rich to capture the most important historical developments in the oil markets. We find that the impact of uncertainty on the oil price show substantial time variation. Although the effect of uncertainty on the oil price had several breaks, it is found to be mostly significant and positive. Indeed, uncertainty has a significant and positive effect on the oil price between 1994 and 2013. There are four periods where the coefficient measuring the effect of uncertainty had sharp breaks and even become negative. These periods correspond to the historical events of the collapse of OPEC in 1986, invasion of Kuwait in 1990/91, Asian crisis in 1997/2000 and the Global Financial Crisis in 2008. Another significant finding of our study is the highly time-varying nature of the volatility. The estimates of the stochastic volatility model show that volatility shocks play a significant role and oil price volatility display significant persistence. Indeed, large positive volatility shocks and extremely high volatility periods are followed by declining oil prices and effect of uncertainty becomes insignificant or 
even negative. We also find evidence that oil price has a negative but small effect on its volatility.

For future research, it would be interesting to investigate whether the time-varying parameter variants of the stochastic volatility model also fit other macroeconomic or financial time series better than the other models used in the literature.

\section{References}

Aguerrevere, F. L. (2009). Real options, product market competition, and asset returns. The Journal of Finance, 64(2), 957-983.

Alquist, R., Kilian, L., and Vigfusson, R. J. (2013). Forecasting the price of oil. Handbook of economic forecasting, 2, 427-507.

Baumeister, C., and Kilian, L. (2016a). Lower oil prices and the US economy: is this time different. Brookings papers on economic activity. https://www. brookings. edu/bpeaarticles/lower-oil-prices-and-the-us-economy-is-this-time-different.

Baumeister, C., and Kilian, L. (2016b). Forty years of oil price fluctuations: Why the price of oil may still surprise us. The Journal of Economic Perspectives, 30(1), 139-160.

Behmiri, N. B., and Manera, M. (2015). The role of outliers and oil price shocks on volatility of metal prices. Resources Policy, 46, 139-150.

Bernanke, B. S. (1983). Irreversibility, uncertainty, and cyclical investment. The Quarterly Journal of Economics, 98(1), 85-106.

Bhatia, V., Das, D., Tiwari, A. K., Shahbaz, M., and Hasim, H. M. (2018). Do precious metal spot prices influence each other? Evidence from a nonparametric causality-in-quantiles approach. Resources Policy, 55, 244-252. 
Blake, A. J., and Roberts, M. C. (2006). Comparing petroleum fiscal regimes under oil price uncertainty. Resources Policy, 31(2), 95-105.

Bredin, D., Elder, J., and Fountas, S. (2011). Oil volatility and the option value of waiting: An analysis of the G-7. Journal of Futures Markets, 31(7), 679-702.

Brennan, M. J. (1990). Latent assets. The Journal of Finance, 45(3), 709-730.

Brennan, M. J., and Schwartz, E. S. (1985). Evaluating natural resource investments. Journal of business, 135-157.

Canova, F. (1993). Modelling and forecasting exchange rates with a Bayesian time-varying coefficient model. Journal of Economic Dynamics and Control, 17(1-2), 233-261.

Chan, J. C. (2017). The stochastic volatility in mean model with time-varying parameters: An application to inflation modeling. Journal of Business \& Economic Statistics, 35(1), 17-28.

Charles, A., and Darné, O. (2014). Volatility persistence in crude oil markets. Energy policy, $65,729-742$.

Chesney, M., and L.O. Seott (1989). Pricing European options: a comparison of the modified Black-Seholes model and a random variance model. Journal of Financial and Qualitative Analysis, 24, 267-284.

Chua, C. L., Kim, D., and Suardi, S. (2011). Are empirical measures of macroeconomic uncertainty alike?. Journal of economic surveys, 25(4), 801-827.

Clark, P.K. (1973). A subordinated stochastic process model with fixed variance for speculative prices. Econometrica, 41, 135-156.

Cogley, T., and Sargent, T.J. (2001). Evolving Post-World War II US Inflation Dynamics. NBER Macroeconomics Annual 16, 331-388.

Cogley, T., and Sargent, T. J. (2005). Drifts and volatilities: monetary policies and outcomes in the post WWII US. Review of Economic dynamics, 8(2), 262-302. 
Danielsson, J. (1994). Stochastic volatility in asset prices estimation with simulated maximum likelihood. Journal of Econometrics, 64, 375-400.

D'Agostino, A., Gambetti, L., and Giannone, D. (2013). Macroeconomic forecasting and structural change. Journal of Applied Econometrics, 28(1), 82-101.

Davidian, M., Carroll, R.J. (1987). Variance function estimation. Journal of the American Statistical Association, 82, 1079-1091.

Dutta, A. (2018). Impacts of oil volatility shocks on metal markets: A research note. Resources Policy, 55, 9-19.

Elder, J., and Serletis, A. (2009). Oil price uncertainty in Canada. Energy Economics, 31(6), $852-856$.

Elder, J., and Serletis, A. (2010). Oil price uncertainty. Journal of Money, Credit and Banking, 42(6), 1137-1159.

Elder, J., and Serletis, A. (2011). Volatility in oil prices and manufacturing activity: An investigation of real options. Macroeconomic Dynamics, 15(S3), 379-395.

Edelstein, P., and Kilian, L. (2007). The Response of Business Fixed Investment to Changes in Energy Prices: A Test of Some Hypotheses about the Transmission of Energy Price Shocks. The B.E. Journal of Macroeconomics (Contributions) 7, Article 35. http://www.bepress.com/bejm/vol7/iss1/art35/.

Edelstein, P., and Kilian, L. (2009). How sensitive are consumer expenditures to retail energy prices?. Journal of Monetary Economics, 56(6), 766-779.

Engle, R. F., Lilien, D. M., and Robins, R. P. (1987). Estimating time varying risk premia in the term structure: the ARCH-M model. Econometrica: Journal of the Econometric Society, 391-407.

Ferderer, J. P. (1997). Oil price volatility and the macroeconomy. Journal of macroeconomics, $18(1), 1-26$. 
Gibson, R., and Schwartz, E. S. (1990). Stochastic convenience yield and the pricing of oil contingent claims. The Journal of Finance, 45(3), 959-976.

Granger, C.W.J., and Newbold, P. (1976). Forecasting transformed series. Journal of the Royal Statistical Society, 38, 189-203.

Henry, C. (1974). Investment decisions under uncertainty: the" irreversibility effect". The American Economic Review, 64(6), 1006-1012.

Hooker, M. A. (1996). What happened to the oil price-macroeconomy relationship? Journal of monetary Economics, 38(2), 195-213.

Hull, J., and White, A. (1987). The pricing of options on assets with stochastic volatilities. Journal of Finance, 42, 281-300.

Kilian, L. (2010). Oil price volatility: Origins and effects (No. ERSD-2010-02). WTO Staff Working Paper.

Kilian, L. (2014). Oil price shocks: causes and consequences. Annu. Rev. Resour. Econ., 6(1), 133-154.

Kilian, L. (2016). The impact of the shale oil revolution on US oil and gasoline prices. Review of Environmental Economics and Policy, 10(2), 185-205.

Kilian, L., and Vigfusson, R. J. (2011). Are the responses of the US economy asymmetric in energy price increases and decreases?. Quantitative Economics, 2(3), 419-453.

Kim, S., Shephard, N., and Chib, S. (1998). Stochastic volatility: likelihood inference and comparison with ARCH models. The review of economic studies, 65(3), 361-393.

Koop, G., and Potter, S. M. (2007). Estimation and forecasting in models with multiple breaks. The Review of Economic Studies, 74(3), 763-789.

Koopman, S. J., and Hol Uspensky, E. (2002). The stochastic volatility in mean model: empirical evidence from international stock markets. Journal of applied Econometrics, 17(6), 667-689. 
Majd, S., and Pindyck, R. S. (1987). Time to build, option value, and investment decisions. Journal of financial Economics, 18(1), 7-27.

Meddahi, N., and Renault, E. (2004). Temporal aggregation of volatility models. Journal of Econometrics, 119(2), 355-379.

Organisation of the Petroleum Exporting Countries (OPEC) (2014). Annual Statistical Bulletin

2014. Vienna, Austria, https://www.opec.org/opec_web/static_files_project/media/downloads/publications/ASB 2014.pdf.

Phillips, P. C., and Perron, P. (1988). Testing for a unit root in time series regression. Biometrika, 335-346.

Pindyck, R., (1991). Irreversibility, uncertainty, and investment. Journal of Economic Literature 29, 1110-1148.

Primiceri, G. E. (2005). Time varying structural vector autoregressions and monetary policy. The Review of Economic Studies, 72(3), 821-852.

Radetzki, M. (2006). The anatomy of three commodity booms. Resources Policy, 31(1), 56-64. Raza, N., Shahzad, S. J. H., Tiwari, A. K., \& Shahbaz, M. (2016). Asymmetric impact of gold, oil prices and their volatilities on stock prices of emerging markets. Resources Policy, 49, 290-301.

Reboredo, J. C. (2013). Is gold a hedge or safe haven against oil price movements?. Resources Policy, 38(2), 130-137.

Salisu, A. A., and Fasanya, I. O. (2013). Modelling oil price volatility with structural breaks. Energy Policy, 52, 554-562.

Said, S. E., and Dickey, D. A. (1984). Testing for unit roots in autoregressive-moving average models of unknown order. Biometrika, 71(3), 599-607. 
Shephard, N. (1996). Statistical aspects of ARCH and stochastic volatility. In: Time Series Models in Econometrics, Finance and Other Fields, (edited by D.R. Cox, David V. Hinkley and Ole E. Barndorff-Neilsen), 1-67. London: Chapman \& Hall.

Stock, J. H., and Watson, M. W. (1996). Evidence on structural instability in macroeconomic time series relations. Journal of Business \& Economic Statistics, 14(1), 11-30.

Taylor, S.J. (1986). Modelling Financial Time Series. John Wiley, Chichester.

Taylor, S.J. (1994). Modelling stochastic volatility. Mathematical Finance, 4,183-204.

Tauchen, G., and Pitts, M. (1983). The price variability volume relationship on speculative markets. Econometrica, 51, 485-505.

Triantis, A. J., and Hodder, J. E. (1990). Valuing flexibility as a complex option. The Journal of Finance, 45(2), 549-565. 